\title{
BIOGAS TECHNOLOGIES FOR SUSTAINABLE IMPROVEMENT OF ENERGY DIVERSITY
}

\author{
Mohammed Balubaid ${ }^{1}$, Rami Al Amoudi ${ }^{1}$, Ahmed A. Bakhsh ${ }^{1}$, Osman Taylan ${ }^{1}$, Fatma ÇANKA KILIÇ²*, \\ Durmus Kaya $^{2}$, and Basil Al Sasi ${ }^{1}$ \\ ${ }^{1}$ Department of Industrial Engineering, Faculty of Engineering, King Abdulaziz University, \\ Jeddah 21589, P.O. Box 80204, Saudi Arabia; \\ ${ }^{2}$ Department of Energy Systems Engineering, Faculty of Technology, Kocaeli University, Umuttepe Yerleşkesi, \\ 41380, Izmit/Kocaeli, Turkey;
}

*Corresponding Author Fatma ÇANKA KILIÇ, e-mail: fatmacanka@ hotmail.com; E-mail addresses: mbalubaid@kau.edu.sa (M. A. Balubaid,), rhalamoudi@kau.edu.sa (R. H. Al Amoudi), aabakhsh@kau.edu.sa (A. A. S. Bakhsh), otaylan@kau.edu.sa (O. Taylan), fatmacanka@ hotmail.com (Fatma ÇANKA KILIÇ)*, durmus.kaya@kocaeli.edu.tr (D. Kaya), balsasi@kau.edu.sa (B.O. Al-Sasi).

Received June 2019; Accepted July 2019; Published January 2020;

DOI: https://doi.org/10.31407/ijees10.102

\begin{abstract}
The purpose of this study is to measurably assess an integrated industrial biogas plant and introduce some biogas technologies as alternative sources for energy production in the Kingdom of Saudi Arabia. Biodegradable materials such as organic wastes, sewage, municipal wastes, and green wastes are very important precursors used in energy production plants for obtaining biogas and some certain organic fertilizers. Biogas plants have many benefits; one of their primary functions is being used as anaerobic digesters with different configurations to treat animal and agricultural wastes for energy production. During the process, microorganisms convert biomass wastes into biogas, mainly methane and carbon dioxide. The study shows four steps carried out of a full-scale biogas plant for a life cycle analysis (LCA) with $950 \mathrm{kWh}$ as: initially, the scope and target were defined, then inventory was analysed, the impact was assessed, and finally the results were interpreted in detail. The results of analysis showed that the biogas plant can preclude the equivalent of $2.43 \mathrm{E}+09 \mathrm{~kg}$ of $\mathrm{CO}_{2}$ global warming and the ozone depletion of $18.80593 \mathrm{~kg}$ of CFC-11 equivalent. It was also determined that aquatic environment eutrophication contributed to the prevention of toxicity, acidification, and eco-toxicity for humans. Some organic by-products were obtained from anaerobic digestion (AD) and used as fertilizer for agricultural or other productions.
\end{abstract}

Keywords: Biogas, Biogas plant, Anaerobic digester, Life cycle analysis (LCA), Inventory analysis 